\title{
Research on Satellite Application Industry Development in China
}

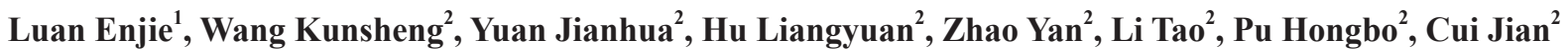 \\ 1. State Administration of Science, Technology and Industry for National Defense, Beijing 100088, China \\ 2. China Aerospace Academy of Systems Science and Engineering, Beijing 100048, China
}

\begin{abstract}
Satellite application industry is the key development direction of the emerging strategic high-end equipment manufacturing industry in China. With the objective of defining the concept and scope of the satellite application industry, this paper provides an overview of the domestic and international development status, problems in focus, and trends in this field. Policy suggestions to promote the satellite application industry are proposed in this paper, including enhancing innovation capability, accelerating highprofile project implementation, improving the policy environment, persisting in military-civil integration development, and adopting a globalization strategy.
\end{abstract}

Keywords: satellite application; space infrastructure; emerging strategic industries; space powers

\section{Introduction}

Satellite application industry, being a high-end equipment manufacturing industry, is a key development direction for the emerging strategic industry in China, and it is the focus of the aviation and aerospace equipment domain of the Made in China 2025 plan. Therefore, accelerating the development of satellite application, improving the civil space infrastructure; upgrading satellite capabilities in remote sensing, communication, and navigation; and promoting space technology transformation and application are of significance, and will lead technological innovation and scientific discovery, make a great contribution to the military-civil integration development, and fulfill the China's dream of space power.

This paper is an abstract of the CAE Major Advisory Project "Research on Promotion and Development Planning of China's Strategic Emerging Industry in the 13th Five-Year Plan Period." After defining the concept and scope of the satellite application industry, the paper provides an overview of domestic and inter- national development, existing problems, and trends in this field. Several suggestions to promote the satellite application industry are proposed, such as enhancing innovation capability, accelerating major projects implementation, improving the policy environment, persisting in the military-civil integration development, and adopting a globalization strategy.

\section{Concept and scope of the satellite application industry}

As defined by the Satellite Industry Association (SIA), the satellite industry is composed of satellite manufacturing, launching services, ground equipment manufacturing, and satellite operation services, while the satellite application industry is composed of ground equipment manufacturing and satellite operation services [1]. According to the Organization for Economic Co-Operation and Development (OECD), the satellite industry refers to the industrial domain made up of satellite manufacturing, launching, and related services, covering all economic activities

Received date: 21 May 2016; revised date: 21 June 2016

Author information: Luan Enjie, State Administration of Science, Technology and Industry for National Defense, academician of Chinese Academy of Engineering. His current research is in control theory and systems engineering. E-mail: pepsijian@163.com

Foundation item: CAE Major Advisory Project "Research on Promotion and Development Planning of China's Strategic Emerging Industry in the 13th Five-Year Plan Period (No. 2014-ZD-7)

Chinese version: Strategic Study of CAE 2016, 18 (4): 076-082

Cited item: Luan Enjie et al. Research on Satellite Application Industry Development in China. Strategic Study of CAE, http://10.15302/J-SSCAE-2016.04.012 
related to satellite manufacturing, launching, and application [2]. Both concepts above imply that the satellite application industry is a part of the whole satellite industry chain, comprising satellite manufacturing, launch vehicle manufacturing, launch services, satellite application, ground equipment manufacturing, and other activities; while in the industrial domain, the satellite application industry includes satellite communication, satellite navigation, satellite remote sensing, space science explorations, and other fields. In general, the satellite application industry covers two major space activities, including spatial infrastructure construction and the satellite application.

Therefore, the satellite application industry is a high-tech industry in China and is composed of spacecraft manufacturing, launch vehicle manufacturing, ground equipment manufacturing, launch services, operational services, and other complete industrial chain. The core of the satellite application industry is to establish self-reliant, secure, reliable, and long-term-operating spatial infrastructure and related information service systems. The focus areas of it are satellite communication, navigation, remote sensing, and market-driven comprehensive applications, along with space exploration and experiments, mainly including the space transportation, applied satellites, scientific experiment satellites, terrestrial systems, and satellite application. In general, the satellite application industry comprises both the spatial infrastructure construction and the satellite application [3].

Spatial infrastructure, as a part of the national strategic infrastructure systems, refers to the space-ground integrated system. It is built up with the space technologies and is composed of application-oriented spacecraft such as various kinds of satellites with matching function and ground systems. It aims to effectively utilize outer-space (including near space) resources and environment, enlarge the human activity boundary, and provide long-term, continuous, stable, and systematic public services for national security, social economy development, social welfare improvement, and scientific technology advancement. Space infrastructure includes applied satellites used for communication, navigation, and remote sensing; near-space spacecraft for business; ground supporting systems; ground date and service systems; and supporting environment. It can provide basic products and services for an extensive range of applications, such as global comprehensive observation, information transmission, and navigation [4].

The satellite application industry is the collection of the technologies, products, services, and industry relying on space infrastructure for the sake of national economy, social development, scientific research, and other areas. The satellite application industry includes two parts_-ground equipment manufacturing and operational services.

\section{Development of the satellite application industry}

\subsection{Domestic and international overview}

The satellite application industry has witnessed explosive development worldwide in the 21 st century. The overall revenue of the global satellite industry in 2014 reached 203 billion USD with a growth rate of $4 \%$, while global economic growth was $2.6 \%$ during the same period [5]. More than $60 \%$ of the global satellite industry revenue was contributed by satellite application, while the satellite manufacturing and launch contributed $11 \%$.

For many years, a suitable development path driven by self-innovation has shaped with China's characteristics for the satellite application industry. The China's satellite application industry has made a series of important achievements. China has the second-largest number of in-orbit satellites in the world. The communication satellite business in China involves fixed, relay-operated, and direct broadcast satellites, and the communication frequency band covers $\mathrm{S}, \mathrm{C}, \mathrm{Ku}, \mathrm{Ka}$, and other bands ${ }^{\dagger}$. China is one of the few countries capable of developing highvolume communication satellites. The regional Beidou satellite navigation system (BDS) has been developed. The BDS offers services involving reliable positioning and high-precision navigation, timing, and short-message transmission in the Asia-Pacific region. The global BDS, with its ability to provide services worldwide, is expected to be completed by 2020. China has developed various series of remote sensing satellites for natural resources, oceans, weather, and environmental disaster reduction. Observing the earth from space is entering a high-resolution age with the space resolution in the sub-meter range.

Although the overall scale of the satellite application industry has exceeded 100 billion yuan in China, there is still much room for improvement. The scale of the satellite communication industry in China was about 20 to 30 billion yuan in 2013 . Meanwhile, satellite navigation and positioning services formed a business of 104 billion yuan, of which the output value of BDS reached 10 billion yuan. Satellite remote sensing is relatively small in scale; nevertheless, the scale of the geographical information industry, combining navigation and remote sensing, is nearly 260 billion yuan annually [6].

\subsection{The current status of satellite applications}

\subsubsection{Satellite communication}

The industrial chain of global satellite communication is composed of satellite manufacturing and launch service, ground equipment manufacturing (including system integration), and op-

† S frequency band: 1.55-3.4 GHz band; C frequency band: 4.0-8.0 GHz band; Ku frequency band: $12-18 \mathrm{GHz}$ band; Ka frequency band: $26.5-$ $40 \mathrm{GHz}$ band. 
eration services. Satellite communication business involves commercial satellite communication, fixed satellite communication, and mobile satellite communication. The commercial satellite communication includes multimedia businesses such as satellite TV direct broadcast, satellite broadcast, and satellite broadband multimedia. The global market scale of the satellite communication reached 121.3 billion US dolloars in 2014, with 100.9 billion US dolloars from the commercial satellite communication, out of which 95 billion US dolloars was contributed by satellite TV direct broadcast. Meanwhile, the market scale of the fixed satellite communication and mobile satellite communication reached 17.1 billion US dolloars and 3.3 billion US dolloars, respectively.

China has developed the Dongfanghong (DFH)-2, DFH-3, DFH-4, and DFH-5 platforms for communication satellites and formed a series of fixed, relay-operated, and direct broadcast satellites, with the communication brand covering the $\mathrm{S}, \mathrm{C}, \mathrm{Ku}$, $\mathrm{Ka}$, and other bands, containing various communication satellite levels from small satellites to ultra-large satellites. The DFH-3 platform serves communication, relay, navigation, and lunar exploration business. The DFH-4 platform is of high performance and quality, which is widely recognized both in China and abroad. The DFH-5 platform project has been initiated successfully, featuring the new generation of large truss-type geostationary earth orbit (GEO) satellite platform developed independently by China. The DFH-5 platform, with its characteristics of high load-bearing, high power, high heat dissipation, long service life, and extendibility, has been included in the "One Belt One Road" national economic development strategy.

In China, the primary business sectors in the satellite communication market are fixed communication, broadcasting, and ground equipment manufacturing. Fixed satellite communication services mainly involve satellite transponder leasing, special and public very small aperture terminal (VSAT) satellite communication networks, special line communication of satellites, etc. The main service providers include China Satcom, China Telecom, and VSAT operators, with various types of fixed, mobile and portable satellite ground stations being more than 100 000. Satellite broadcasting services mainly cover satellite digital audio radio, satellite TV transmission, and satellite TV direct broadcast. The satellite TV direct broadcast mainly serves for public benefit through the "Every Village Project" and "Every Household Electricity Project". The ground equipment products are mainly applied to government emergency support systems (i.e., emergency support vehicles, ground main stations, and ground mini stations). TV set-top boxes, terminal receivers (including satellite antennas), and ground station equipment are mainly used in satellite broadcasting communication systems. While the personal handheld terminals and mobile satellite antennas are mainly adopted in personal mobile communication, scientific investigation, exploration, tourism, and journalism.

In comparison to developed countries, the satellite communication industry in China is in the growth stage with a large gap where technologies and scales are concerned. Operation services in the downstream industries of the industrial chain of satellite communication have a larger economic scale compared to the relatively smaller scale of the upstream industries of ground equipment manufacturing. There are few major entities achieving economies of scale in China's satellite communication industry. In addition, the applications and commercialization of the satellite TV direct broadcast in China is still in the inception stage. China does not have its own broadband multimedia satellites. The demands of mobile satellite communication applications in China are rather urgent.

\subsubsection{Satellite navigation}

The industrial chain of satellite navigation consists of navigation satellite manufacturing and launch, basic products, terminal products, system integration, and operation services [7]. According to the European Global Navigation Satellite System (GSA), the revenue of the positioning-navigation-timing (PNT) market reached 91.3 billion US dolloars by 2014. Terminal products based on global navigation satellite systems (GNSSs) have become the core application in this field, including smart phones, personal navigation terminals, aviation, precision agriculture, and search-and-rescue terminals. The shares of the US Global Positioning System (GPS), European Galileo Satellite Navigation System (Galileo), China's Beidou Navigation Satellite System (BDS), and other GNSS industries are $31 \%, 25.8 \%, 7 \%$, and $36 \%$, respectively ${ }^{\dagger}[8]$.

As an important part of the national spatial infrastructure, BDS started offering services to China and the surrounding areas at the end of 2000. By the end of 2012, BDS officially began offering services to major areas of the Asia-Pacific region. It is anticipated that BDS will provide global services before 2020. The BDS application witnessed many crucial technology breakthroughs, from antenna to terminal, from single system to multi-mode-multi-band (MMMB) communication system, from prototype to product, and from product to systematic solution. The products forms in this field span the whole industrial chain, including antennas, chips, modules, digital maps, simulators, and application solutions. The BDS industrial system has formed preliminarily, consisting of basic product, application terminal, and operation service. With competitive quality and price of the counterparts in abroad markets, the sales volume of BDS products has reached more than 6 million. The products has been widely applied to transportation, marine fishery, hydrological monitoring, weather forecasting, geodetic surveying, disaster

\footnotetext{
$\dagger$ Based on the income date of 900 companies involved in GNSS in 2012.
} 
relief and mitigation, mobile navigation, and more, resulting in significant social and economic benefits. At present, BDS has been recognized as the third satellite navigation system in the world by the International Maritime Organization (IMO).

The satellite navigation industry is mainly based on GPS in China. At present, there are over 10000 corporations and more than 300000 employees involved in satellite navigation and positioning services, the majority of which are small enterprises. Domestic brands are trying to occupy the consumer terminal market through low-price competition. Lack of core technology in the upstream industries of the chain results in low added value of the products for most domestic enterprises. In general, the satellite navigation industry is in the growth stage in China.

\subsubsection{Satellite remote sensing}

The industrial chain of the satellite remote sensing industry consists of remote sensing satellite manufacturing and launch services, remote sensing data receiving, remote sensing data processing and distribution, and remote sensing information value-added services. The value of global commercial remote sensing data and value-added products reached 2.3 billion US dolloars in 2014 and is estimated to reach 5.1 billion US dolloars by 2024 [9].

Satellite remote sensing in China serves mainly public welfare demands such as meteorology, oceanography, surveying and mapping, and disaster prevention and mitigation. The meteorological satellite "FY" (Fengyun, or Wind and Cloud) series has global 3D multi-spectral quantitative observation capability, which enable effective surveillance of typhoons, floods, forest and prairie fires, droughts, sand storms, and snow disasters. The Earth resource satellite "ZY" (Ziyuan, or Resources) series play an important role in resources and geologic hazard investigation, surveillance and management of land, geological minerals, agriculture, forestry, and water, as well as in urban planning. The Ocean satellite "HY" (Haiyang, or Ocean) series enable surveillance and application of China's waters and other key waters in the world. They have improved significantly in their forecast accuracy of sea surface height, sea surface temperature, sea-surface wind field, and ocean waves; meanwhile, they have enhanced surveillance effectiveness for disastrous ocean conditions. The Environment satellite "HJ" (Huanjing, or Environment) series provide important technical support for monitoring surface water quality and ecological environment as well as tracking emergency pollution such as oil spills and water bloom.

With the implementation of the high-resolution earth observation project, China has launched five high-resolution earth observation satellites, changing prolonged domination of foreign countries in high-resolution satellite "GF" series market. GF-1 is the first satellite of the project and is a low-orbit remote sensing satellite that has a life examined to be greater than 5 years. The spatial resolution of GF-2 is better than $1 \mathrm{~m}$ and has a high radiant accuracy, high positioning accuracy, and the ability to maneuver quickly. GF-4 is the first remote sensing satellite in geosynchronous orbit, which uses area array staring technology to image, with visible, multispectral, and infrared imaging capabilities. Its visual and spectral resolution is better than $50 \mathrm{~m}$, and its infrared spectral resolution is better than $400 \mathrm{~m}$; GF-4 is designed with an eight-year life span. GF-8 is an optical remote sensing satellite in the Earth-geosynchronous orbit with a panchromatic resolution of $50 \mathrm{~m}$. GF-9, with sub-meter resolution capability, provides information assurance for the "One Belt One Road" strategy and the modernization of national defense. In addition, the successful launch of Jilin-1 marks an important step in commercialization and industrialization of remote sensing. These satellites will provide remote sensing data support for land resources monitoring, land surveying and mapping, smart cities construction, transport facilities monitoring, agricultural yield estimation, ecological environment monitoring, and disaster reduction and prevention. It is expected that China will launch the first $0.5-\mathrm{m}$ high-resolution commercial remote sensing satellite by 2016 and will construct commercial remote sensing satellite systems with $0.5-\mathrm{m}$ high resolution by 2022 .

\subsection{Major problems}

\subsubsection{Low level of satellite application industrialization}

An application satellite system has formed, consisting of communication satellites, navigation satellites, and remote sensing satellites. However, its contribution to economic and social development is below expectations because of its late start and small scale. The satellite communication market is mainly composed of satellite transponder leasing, the "Every Village Project," and the "Every Household Electricity Project," and has very few commercial applications. Independent navigation products relying on BDS are still in the starting stage. The satellite remote sensing is used to fulfill the demands of public welfare; however, its capability of comprehensive and quantitative applications lags behind relatively without fully taking advantage of the available technology and data.

\subsubsection{Unsound industry policies}

The management regimes of various corporations in the satellite application industry in China are relatively dispersed and are unable to form a joint force. It is difficult to coordinate resources comprehensively, and the usage of space infrastructure and data resources is inefficient. The progress of industrial standardization is slow, and the standards are missing and lagging behind. Commercial remote sensing satellite development is limited by unsound industry norms and data management policies. A lack of definite demarcation and norms for remote sensing data import, export, and application leads to the influx of an unlimited high-resolution data from abroad.

\subsubsection{Fierce market competition}

BDS occupies only approximately $10 \%$ of the market share 
because of its late start, small-scale production, and less development in the civilian market. The competition from GPS is very fierce. The foreign commercial remote sensing services are highly advanced. Companies such as Planet Labs and Skybox have led remote sensing services into times of low cost and big data service. In comparison, the comprehensive application and quantitative application capabilities of satellite remote sensing in China lag behind, without fully taking advantage of the available technology and date, and over $90 \%$ of high-resolution remote sensing data for civil use rely on foreign satellites in China. The carrying capacity of India, Japan, and other countries is maturing in the satellite launch services market. The cost advantage of China's launch services is no longer distinct, owing to the fast development of commercial space companies such as SpaceX. Competition in the commercial launch services market is rather severe, and our current share of the international launch service market is only $3 \%$.

\subsubsection{Ongoing innovation improvement in technology}

There exists a large gap in overall properties and technique levels of satellites between China and developed countries. Some fields are still blank although sorely in need. For example, China has not set up a self-owned satellite system for mobile communication, so it is difficult to obtain a comprehensive security regime for communication, when the satellite mobile communication and satellite broadband services are all from abroad. The areas that require improvement include the longevity and reliability of satellites, satellite platform performance, payload, and core apparatus. In addition, other countries are ahead in the development of crucial techniques, and they dominate in raw material acquisition as well as component and instrument manufacturing. Outdated design and manufacturing techniques lead to longer cycle times for space equipment development and production.

\section{Development trends of the satellite application industry}

\subsection{The development trend of global satellite application industry}

For the next 10 years, the satellite application industry has tremendous potential. According to a newly released Euroconsult report in 2015, 1400 satellites will be built and launched in the world by 2024, and that will bring 255 billion US dolloars in revenues for government agencies and commercial companies. The government agencies still occupy the leading position [10]. In addition, Euroconsult anticipates 40 companies will launch 550 satellites over the decade.

In the satellite communication domain, communicationbroadcast satellites will achieve global coverage and highly commercialized; various business systems are tending to in- tegrate with the development of broadband multimedia services; and China is stepping up the deployment of next-generation mobile satellites. The main driving force behind this phenomenon is the rapid development of satellite multimedia broadcasting in the mass consumption market. Broadband multimedia satellite communications are going to be an important part of the space infrastructure. The satellite TV direct broadcast has become a pillar industry of satellite applications. Mobile satellite communications will develop rapidly. Meanwhile, the role of satellite communication in the government and military fields, such as military communication, environmental data acquisition and monitoring, and national emergency rescue and relief communication will be constantly strengthened.

In satellite navigation, navigation satellite systems are accelerating construction and competition. GNSSs have developed into a situation where four major systems (GPS, GLONASS, Galileo, and BDS) and their regional enhanced systems coexist. Penetration, integration, and convergence with other information systems have become a trend. The global satellite navigation industry has presented three directions - changing from the single GPS application to multi-system compatible application; changing from single navigation to convergence of navigation applications, mobile communication, and Internet; and changing from terminal application to products and services application.

As to the satellite remote sensing, the pattern of remote sensing satellite service tends to be better. The new business mode, with the characteristic that the government and business sectors share the costs of satellite development and launch, will emerge. High resolution Landsat will dominate commercial remote sensing system. Commodity monopolies and brand effects of satellite remote sensing industry will continually increase. Satellite remote sensing technology will be integrated with communication, navigation, and the Internet of things (IoT), and will be widely used. Global Earth observation and services capabilities will be continuously enhanced.

\subsection{Satellite application industry trends in the 13th Five- Year Plan period}

\subsubsection{Satellite communication}

The satellite TV direct broadcast becomes the focus of industrial development. It has the biggest market potential because of the satellite TV demand of approximately 170 million households. This will cause the broadband multimedia satellite and its applications to be developed. China will independently develop geostationary Ka-band satellites, and the satellite broadband access will increase steadily over the next 10 years. The satellite mobile broadcasting market has extraordinary potential. The number of potential users of the global satellite mobile communication system will reach 13 million in China. The domestic market capacity of public products will reach 11 billion yuan, and the revenue growth rate of the satellite communication serv- 
ices will be $10 \%-15 \%{ }^{\dagger}$.

\subsubsection{Satellite navigation}

BDS will continue to build and improve the eco-industrial chain. By 2020, the user scale of the satellite navigation and location services industry in China will become the first in the world. With the acceleration of promotion of BDS into the international civil aviation, maritime, mobile communication, and other markets, BDS will be fully compatible with other global navigation and positioning systems, and fully integrated with the world [11].

\subsubsection{Satellite remote sensing}

The growing demands from all fields are driving the satellite remote sensing applications to be integrated [12]. Satellite remote sensing applications will gradually enter public life. Meanwhile, the resolution of the data source will develop towards the high space, high time and high spectrum. Demand for the indepth development of remote sensing applications will continue to grow. Satellite remote sensing will gradually deepen the scope of application in disaster prevention and mitigation, environmental monitoring, urban planning, resource exploration, precision agriculture, and other fields. Additionally, commercial applications and value-added services based on the remote sensing data will be developed.

\section{Political recommendations for promoting the $d$ evelopment of the satellite application industry}

\subsection{Enhance innovation capability and enable key technique breakthroughs}

It is necessary to increase investment in R\&D and import substitution rate of crucial raw materials, core components, and highend manufacturing facilities, which will lay a sound technology foundation in the satellite application industry. High-profile aerospace projects must be utilized to facilitate key breakthroughs in satellites and related application techniques, leading to progress in satellite communication platform performance, payload, multi-mode multi-function chips, and crucial terminal techniques for communication and broadcast, navigation, and remote sensing. It is necessary to promote transformation of technological achievements and increase the volume of patents and original innovations to support technical progress in the industry and schema innovation in applications.

\subsection{Accelerate high-profile projects implementation and set application models}

Launching the space-ground integration project is conducive to promoting the construction of a spatial information network with the characteristics of a single-satellite multifunction integration, multiple-satellite networking, and multi-network integration. It is also beneficial for breakthroughs in techniques for comprehensive multi-function multi-mode satellite applications. The targets of this project are to speed up the improvement of the data sharing service mechanism, to establish a basic commercial development mode, to develop the capability for delivering services internationally. The implementation of high-profile projects is beneficial to achieving major progress in integrated emergency security of satellite disaster prevention and mitigation, satellite multimedia broadcast communication, positioning service on the base of the BDS, and IoT applications within space-ground integration. Additionally, integrated application demonstration of remote sensing, communication, and navigation should be encouraged and supported in satellite disaster prevention and mitigation, telemedicine, distance education, emergency communication, and precision agriculture.

\subsection{Improve the policy environment and guarantee long- term stable development}

Accelerating policy improvement of the satellite communication industry helps the commercialization of satellite television broadcasting, satellite broadband multimedia, and satellite mobile communication, which promotes the resource utilization of communication satellites. Accelerating policy-making for national satellite remote sensing data, delimiting boundary on data opening, and establishing a data sharing mechanism and standards will promote spatial data information sharing and guarantee security and effective use of data. China should develop the relevant policies for BDS applications as soon as possible to improve the basic supporting system and accelerate the industrialization development. Crucial areas involving national economy and public security must shift to adopt a new service pattern of BDS with combination of other satellite navigation systems. In addition, it is necessary to establish the key technical standards for space infrastructure construction and operation, as well as the services standards for industrialization of satellite application.

\subsection{Adhere to military-civil integration development and exploit commercial market}

It is necessary to establish a market access mechanism, which can delimit the threshold to enter the aerospace industry for private and social capital and increase the government purchase of commercial aerospace products and services. It is also important

\footnotetext{
$\dagger$ Date is based on the research and statistical analysis of the application of the global satellite mobile communication system from 18 ministries and main application industries of the national economy, which is organized by the MIIT.
} 
to explore and establish development funds for the aerospace industry, which can optimize the investment structure, promote the diversification and commercialization development of the investors, and encourage the securitization of aerospace assets in aerospace fields. In addition, an open and sharing mechanism should be set up to facilitate military, civil, and commercial use of aerospace resources, leading to the sharing of major equipment, facilities, and infrastructure resources, as well as the transformation and commercialization of military techniques. Furthermore, China should enhance the policy support to commercial aerospace projects, from the aspects of taxation, talent introduction, financing, and other aspects, in order to build a good environment for commercial development of the satellite application industry.

\subsection{Adopt a globalization strategy and increase international market share}

It is essential to establish a global satellite operating service system, which can improve the global network resources and service capabilities in satellite communication, satellite remote sensing, satellite navigation, and other areas. In addition, China should strengthen international aerospace cooperation, actively take part in international organizations activities and international standards-making process, commit to building a good international environment for satellite application development, and improve the participation of international cooperation projects. The satellite application industry in China should serve the national "going out" and "One Belt One Road" strategies through the construction of a "New Silk Road in the Sky." Furthermore, Developing the satellite application market of countries along the "One Belt One Road" to help the China's satellite application companies to expand internationally, thereby to raise their share in the international market.

\section{References}

[1] Satellite Industry Association. State of the satellite industry report [R]. Washington: SIA, 2015.

[2] Schrogl K U, Rathgeber W, Baranes B, et al. Yearbook on space policy 2008/2009: setting new trends [M]. Berlin: Springer Wien New York, 2011.

[3] China's Institute of Engineering Development Strategies. Consulting project: strategic emerging industries planning of the 13th Five Year period [R]. Beijing: China's Institute of Engineering Development Strategies, 2014. Chinese.

[4] China's Institute of Engineering Development Strategies. Report on the development of China's strategic emerging industries (2013) [M]. Beijing: Science Press Ltd., 2013. Chinese.

[5] Tauri Group. 2015 State of the satellite industry report [R]. Washington: Semiconductor Industry Association, 2015.

[6] Ye Y. Booming trend of geographic information industry [J]. Think Tank of Science \&Technology, 2014 (10): 45-49. Chinese.

[7] General Office of the State Council of the People's Republic of China [J]. The long-term development planning of national satellite navigation industry. Satellite Application, 2013 (6): 3843. Chinese.

[8] The European Commission, the European Global Navigation Satellite Systems Agency. GNSS market report [R]. Prague: the European GNSS Agency, 2015.

[9] Wang D W. Global commercial satellite market competition analysis [J]. Aerospace China, 2015 (12): 13-20. Chinese.

[10] Euroconsult. Satellites to be built \& launched by 2024: World market survey [R/OL]. (2015-08) [2016-05-21]. http://www. euroconsult-ec.com/research/Satellites-built-launched-by-2024brochure.pdf.

[11] Zhang W. Six Satellite Navigation Market Trends in 2014 [N/OL]. China Science Daily, 2014-03-11(07) [2016-05-21]. http://news. sciencenet.cn/sbhtmlnews/2014/3/284448.shtm. Chinese.

[12] Yang B H, Chi T H. Reflections on the development of satellite remote sensing industry in China [J]. High Technology \& Industrialization, 2010, 6 (12): 26-29. Chinese. 